\title{
Use of Videogames among High School Students in México
}

\author{
PhD. Esperanza Viloria Hernández
}

\author{
Professor \\ Autonomous University of Baja California \\ School of Humanities \\ Baja California, México
}

\begin{abstract}
At a national level, videogame consumption represents $15 \%$ of online consumption, and Mexico occupies the second level in the region for the number of hours per spectator per month. The referred age group is 24 to 35 years old, with a clear predominance of men. Recent reports present another significant sector: people 12 to 20 years old who have increased the consumption of online games and the number of hours they remain online. Under these conditions, the goal of the present project was to identify the levels of intensity of use of videogames. A 15-dimension scale was used to achieve this goal and the sample consisted of 428 students. Among the results, game modes stand out along with hours spent and the differences between men and women according to the genre of the videogame used.
\end{abstract}

Keywords: Videogames, Young people, High School Education, Sex

\section{Introduction}

Online games, particularly videogames, are nowadays a very popular activity among young people. In the case of Mexico, a report by the National Institute of Statistics and Geography or INEGI for its acronym in Spanish (INEGI, 2013), describes that $44.5 \%$ of internet users are 12 to 24 years old. The most recent report by INEGI (2015)signals a global increase, since the number went from $44.5 \%$ to $57.4 \%$ of the population being internet users. From these, $70 \%$ use it to access social media.

Along these lines, the 2019 report by the Internet Advertising Bureau (IAB) shows that Mexicans have more devices to connect to the Internet and remain longer online to navigate or do different activities. On average, users navigate for 6 hours in a day, and $67 \%$ of them have internet access, with a growth rate of $3 \%$, which implies 75.8 millions of internet users. Access to smartphones increased by $90 \%$, use of tablets increased by $51 \%$, and virtual reality use by $15 \%$.

It also stands out that 8 out of every 10 Mexicans use video streaming services (76\%), while music/audio services correspond to $46 \%$ of the preference; videogames represent 15\%. These services are consumed between 6 and $9 \mathrm{pm}$ and from $9 \mathrm{pm}$ to $12 \mathrm{am}$. Mexico occupies second place in the region in terms of the number of hours spent per spectator per month (17 hours), and videos per spectator per month (251hours). Time spent online by users tripled in the last years due to the massive growth of cellphone use (IAB, 2019).

Since the IAB report (2016), there is a group of teenagers between 13 and 17 years old who represent the market segment known as generation $\mathrm{Z}$, which is characterized by doing several activities online, including downloading applications, videos, using social media, or watching advertisements (IAB, 2016). Among the habits of Generation Z, there is $25 \%$ use of portable videogame consoles, and $16 \%$ connect to the Internet. The most common time that $61.56 \%$ of them are onlineis between 3pm and 12am, 12\% are online between 12am and 6am. $87 \%$ of these users download applications and pay for them. Another interesting statistic is that, on average, they do 6 different activities, and $90 \%$ of them consider that the internet accompanies them to pass time. Particularly, their interests include sharing images $(68 \%)$ and watching games $(50 \%)$. Generation $\mathrm{Z}$ shows greater dependenceon their mobile devices. To them, the internet is essential;they pay any price to download applications and show great interest in videos (IAB, 2016).

According to market studies, gamers (hardcore) are a group of people who spend a significant part of their income on videogames. On average, $66 \%$ play on mobile devices, $34 \%$ on consoles, $11 \%$ on tablets, and $10 \%$ on PC. Generation $\mathrm{Z}$ is the generation with the greatest presence in the videogame industry in Mexico due to the possibility of updating gameson their devices and having access to different applications or websites. The teenage gamer sector represents a population of 29.7 million (CIU,2019).

Although consumption patterns show some habits of teenagers, it is relevant to mention the increase in the intensity of use, either of devices or the internet, and their dependence on them. 
The intensity of use represents the time that teenagers spend playing videogames, whether they are connected to the internet or not, spending more than 8 hours per day playing continuously or intermittently, which influences their physiological activity, mood, as well as interpersonal, educational, or work relationships. The intensity of use of videogames is also related to three core aspects: time invested, characteristics of the game, and the feeling of wellbeing perceived by the gamer (Clark y Scott, 2009; Pérez-Sánchez \& Torres, 2014).

Considering the level of intensity of the game, some authors state that videogame abuse could be considered an addiction, since alterations in the biological, psychological, and social processes of the person have been reported, affecting their wellbeing and creating an addiction without chemical substances (Arias, Gallego, Rodríguez \& del Pozo, 2012).

In this regard, the Diagnostic and Statistical Manual of Mental Disorders (DSM-5) of the American Psychiatric Association, which is used to diagnose mental disorders, recognized internet gaming disorder in the section recommending conditions for further research, along with caffeine use disorder and other conditions. The DSM-5 notes that gambling disorder is the only behavioral addiction (as opposed to substance abuse), and states that itmust cause significant impairment or distress in several aspects of a person's life. This proposed condition is limited to gaming and does not include problems with the general use of the internet, online gambling, or the use of social media or smartphones.

The main symptoms are permanent preoccupation with gaming; withdrawal symptoms when gaming is taken away or not possible (irritability or anxiety); developing a tolerance, which means they need to spend more time gaming to satisfy the urge; inability to reduce playing and unsuccessful attempts to quit gaming; giving up other activities, losing interest in previously enjoyed activities due to gaming; and a desire to continue gaming despite problems (DSM-5).

Other symptoms shown by gamers are deceiving family members or others about the amount of time spent on gaming, use of gaming to relieve negative moods such as guilt or hopelessness, and they might risk, jeopardize or lose a job or relationship due to gaming.

According to DSM-5 criteria, a diagnosis of internet gaming disorder would require experiencing five or more of these symptoms within a year. It establishes that the condition can include gaming on the internet or any electronic device. In late 2019, the World Health Organization (WHO) announced that in the upcoming edition of the International Classification of Diseases (ICD-11), gaming disorder would be identified as a new disorder. In some countries, including South Korea and China, video gaming has been recognized as a disorder and treatment programs have been established.

Whether internet gaming should be classified as an addiction/mental disorder is the subject of much debate and a growing body of research. There is neurological research showing similarities in changes in the brain between video gaming and addictive substances (Stavropoulos, Beard, Griffiths, M.D. et al., 2018; Van LooyBillieux, 2016). There have also been studies about the behavior of teenagers and its relationship with violent behaviors

(McLean y Griffiths, 2013). Along the same lines, a relationship between social and psychological aspects in LatinAmerican teenagers has been reported (Moncada y Chacón, 2012). Based on this, the present work begins with the following question: What are the levels of use of videogames among High School students?

\section{Method}

To answer the research question, a quantitative research method with a cross-sectional design was proposed(García y Vega, 2009). The goal is to explore the intensity of use of videogames by creating a scale. A first approach is implemented to identify variables, relationships, and conditions under which intensity of use is seen in High School students.

\section{Participants}

The sample is non-probability due to convenience, since access to a public High School in the northern border of Mexico is possible. The institution facilitated access, and participation of 428 students of the first and second year was achieved. Of these students, $49.1 \%$ were female and $50.9 \%$ male.

\section{Instrument}

The instrument used for the study was created in two stages: the first stage consisted of building variables and dimensions and making them operational. Fifteen variables were defined theoretically, as well as 160 questions that were applied to 10 students for internal validation. 
Pearson correlation was used to select the questions, to create a second version. The second stage consisted of applying the second version consisting of 14 variables, with 48 questions. It was applied again to the 428 students to validate it. The variables considered are: 1) Knowledge of classification; 2) Level of competition; 3) Addiction to gambling; 4) Group or individual gaming; 5) Resources/cost;6) Genre and game;7) Gaming mode; 8) Time; 9) Franchise; 10) Generation; 11) Motivation; 12) Devices; 13) Data presented in this document; 14) Socialization (family, partner, friends, work).

\section{Procedure}

For the second application, which is the subject of this report, there were three steps. The first step consisted of giving talks to professors and administrators to help sensitize the students and achieve their disposition to answer the instrument. The second step consisted of installing the link to access the portal where the instrument could be found in the computers of the institution. The third step involved asking the students to go to the information technology department, where a computer was assigned to them so they could answer the questionnaire. On average, it took each student half an hour to answer the instrument.

\section{Results}

The reliability data was obtained after collecting the answers given by the students using the online instrument. This was achieved by using a Cronbach's Alpha. The analysis was performed globally first, considering all the variables, and then it was disaggregated by variable. As can be seen in Table 1, the .909 Alpha indicates that there is a relationship between the 14 integrated variables, so the instrument is valid and measures the intensity of use of videogames.

After performing an analysis by category, it can be said that the main predictors are associated with the knowledge of students regarding the classification of the videogames they buy or play(.500). The low relationship with cost confirms what is reported in the consumption styles of young people in this segment; they play but try to not pay (.074). An appeal to play for more than 8 hours relates to the level of competition or the challenge that a videogame represents (.824). The different videogame modalities are used by the students (.576) and they prefer playing with other players over playing alone (.683). There are differences from the gamer profile (.536), prevalence is greater for men, and they use time from other activities to play videogames.

Table 1. Global and Variable Cronbach's Alpha considered in the instrument $(\mathrm{n}=428)$

\begin{tabular}{l|l|l}
\hline Variable & Alpha & QuestionNumber \\
\hline Global & .909 & 48 \\
\hline Knowledge of Classification & .500 & 3 \\
\hline Cost & .074 & 4 \\
\hline Level of Competition & .824 & 4 \\
\hline GameMode & .576 & 7 \\
\hline Socialization & .683 & 6 \\
\hline Sex & .539 & 6 \\
\hline Time & .621 & 6 \\
\hline
\end{tabular}

Own creation based on the answers of the intensity of use of videogames instrument.

Regarding the control expressed by participants about the intensity of use of online gaming, $2(\mathrm{M}=4.08, \mathrm{SD}=1.29)$ was identified, which showed a more graphic content in those considered strategy games, compared to neutral videogames, or with less violence $2(\mathrm{M}=1,41, \mathrm{SD}=0,89), \mathrm{F}(1,97)=146,97, \mathrm{p}, 0,001$, gp2 $=0,60$.

When the information was disaggregated according to sex, $60 \%(n=125)$ of women expressed being interested in computer games, since it allows for greater social interaction with virtual persons. Said characters show a nonsexualized role of female protagonists, and the content is considered non-aggressive. Thus, the selection of the type of game must have two characteristics: it allows social interaction and shows moderate violence (59.1\%). In the case of men, 70\% ( $\mathrm{n}=149)$ assigned a greater value to videogames with female protagonists with more sexualized roles and greater interest in strategy activities and violence (90\%), and a lower proportion assigns a value to social interaction $(10 \%)$. The preferences shown are a product of the predetermined games for the study and the preference patterns cannot be strongly stated because other samples and types of games would be needed.

A comparison between the answers of men and women regarding the intensity of use of videogames depending on modality found that men use competitive genres significantly more than women. In contrast, no differences were observed regarding competitive and simulation games (racing, combat flight) 
Additionally, when analyzing the classification of videogames and their contents, it was found that $70 \%$ of them show scenes of death, destruction of objects, and some type of violence, which agrees with the statements of Strasburger, Jordan \& Donnestein from 2010 and the data reported by Moncada \& Chacón in 2012. In this sense, the data reported in the research are similar to those already reported, adding improvements and image quality according to technology advancements.

Re-classification is suggested in the case of Mexico, because users are increasingly younger and they have access to technology via smartphones and tablets, which exposes them to situations that could be negative, considering their stages of psychological development.

\section{Conclusion}

The videogame market is one of the most profitable in the technology segment, since it shows accelerated growth in terms of the number of users and the hours they spend consuming per day. There is evidence in the instrument use that the time variable requires consideration to explain the abuse of videogames. Exploring other categories that result in negative patterns, such as consumption, abstinence, and tolerance after spending more than 10 hours playing should be considered. The validity and reliability of the instrument should also be worked on, using more robust probability samples that allow inferring and generalizing results for a population in topics related to spending on games, level of competition, types of games, and socialization levels.

\section{Referencies}

Arias Rodríguez O. Gallego Peña, V.Rodríguez Niztal, M. J.,\& Del Pozo López, M.A., (2012). Psicología de las adicciones. Vol. 1, pp. 2-6.

Clark, N., y Scott, P.S. (2009). Game Addiction. The experience and the effects. London, McFarland \& Company.

Clasificación Internacional de Enfermedades CIE-11 (2019) Herramientas de codificación, retreived from https://icd.who.int/es

Competitive Intelligence Unit (2019). Author. http://www.the-ciu.net/nwsltr/591Distro.html

García Cabrero, B., \& Vega Pérez, L. (2009). Manual de métodos de la investigación para las Ciencias Sociales. México; El Manual Moderno.

Instituto Nacional de Estadística y Geografía (INEGI;2013). Author.

Instituto Nacional de Estadística y Geografía (INEGI;2015). Author.

Internet Advertising Bureau (2013). Author.Recuperado http://www.iabmexico.com/estudios/consumo-medios-2016/ Internet Advertising Bureau (2019). Author. Retrieved fromhttps://www.iabmexico.com/

Manual de Diagnóstico y Estadística de los Trastornos Mentales DSM-5 (2016). México, Panamericana

McLean, L., y Griffiths, M. (2013). The psychological effects of videogames on young people: A review. Aloma, 31(1), 119-133.

Moncada, J.J., y Chacón, A.Y. (2012). Efectos de los videojuegos en variables sociales, psicológicas y fisiológicas en niños y adolescentes. RETOS. Nuevas Tendencias en Educación Física, Deporte y Recreación, no. 21, January-June, pp. 43-49.

Organización Mundial de la Salud (2019). Hacia una mejor delimitación del trastorno por uso de videojuegos. Retrieved fromhttps://www.who.int/bulletin/volumes/97/6/19-020619/es/

Pérez-Sánchez, R., y Torres, D. (2014). Intensidad de demanda de los videojuegos y su efecto sobre el estado de ánimo y la actividad percibida. Universitas Psychologica, 13, (4).

Stavropoulos, V. Beard, C. Griffiths, M.D. et al. (2018). Measurement Invariance of the Internet Gaming Disorder Scale-Short-Form (IGDS9-SF) Between Australia, the USA, and the UK. International JournalMent Health Addiction, 16, 377-392. https://doi.org/10.1007/s11469-017-9786-3

Strasburger, V. C., Jordan, A. B., \& Donnerstein, E. (2010). Health effects of media on children and adolescents. Pediatrics, 125(4), 756-767

Van Rooij, A. J., Van Looy, J., \& Billieux, J. (2016). Internet gaming disorder as a formative construct: implications for conceptualization and measurement. Psychiatry and Clinical Neurosciences. 71, 445-458, doi:10.1111/pen. 12404.

Wood, T.A.R. (2008). Problems with the concept of video game "Addiction": Some case Study Examples. Int.J. Ment Health Addiction, 6, 169-178 